EXTENDED REPORT

\title{
Efficacy of etanercept in the treatment of acute, severe sciatica: a pilot study
}

S Genevay, S Stingelin, C Gabay

See end of article for authors' affiliations .....................

Correspondence to: Dr S Genevay, Division of Rheumatology, University Hospital of Geneva, 26 avenue Beau-Séjour, 1211 Geneva 14, Switzerland; stephane.genevay@ houge.ch

Accepted 10 March 2004 Published online first 28 April 2004
Objectives: To explore the efficacy of a tumour necrosis factor $\alpha$ (TNF $\alpha$ ) inhibitor (etanercept, Enbrel) in patients with severe sciatica.

Methods: A pilot study of etanercept was conducted in patients admitted to hospital for acute severe sciatica. Ten consecutive patients received three subcutaneous injections of etanercept $(25 \mathrm{mg}$ every 3 days) in addition to standard analgesia. Response was evaluated at day 10 (T1) and week 6 (T2) using a visual analogue scale for leg pain (VASL) and for low back pain (VASB), and two validated functional scores: the Oswestry disability index (ODI) and the Roland Morris disability questionnaire (RMDQ). The control group consisted of 10 patients with severe sciatica, who took part in an observational study on IV methylprednisolone.

Results: In the etanercept group all variables improved: VASB from 36 to 7; VASL from 74 to 12; RMDQ from 17.8 to 5.8, and ODI from 75.4 to 17.3; all $p<0.001$. Pain (VASL and VASB: $p<0.001$ ) and ODI $(p<0.05)$ were significantly better in the etanercept group than in the methylprednisolone group.

Conclusion: In this open, historical group controlled study, patients with severe sciatica had sustained improvement after a short treatment with etanercept that was better than standard care plus a short course of methylprednisolone. These results suggest that inhibition of TNF $\alpha$ is beneficial in the treatment of sciatica and support a pathological role for TNF $\alpha$ in the pathogenesis of sciatica. These results need to be confirmed by a randomised controlled trial.
$\mathrm{L}$ ow back pain is a common clinical problem with enormous medical, social, and financial implications. A subgroup of patients with this problem may present with pain radiating into the leg. This is often called sciatica, when clinical signs of nerve root irritation are present (positive straight leg raising test) and the pain follows a radicular pattern. At times a corresponding neurological deficit can be found. Mixter and Barr were the first to describe the presence of a herniated disc in the vicinity of the affected nerve root. ${ }^{1}$ Standard pharmacological treatment consists of simple analgesics and non-steroidal anti-inflammatory drugs (NSAIDs), the role of steroids being more controversial. With this treatment up to $20 \%$ of patients may require surgical intervention and $10-15 \%$ will develop chronic pain and handicap, leading to significant direct and indirect costs. ${ }^{2}{ }^{3}$

Lack of concordance between clinical and surgical findings has been documented since the forties. More recently, studies using magnetic resonance imaging (MRI) and computed tomography (CT) scanning have shown that up to $20 \%$ of asymptomatic subjects have radiological evidence of intravertebral disc protrusion or herniation. ${ }^{4}$ Recently, also, repetition of earlier functional studies confirmed that pinching of a normal lumbar nerve root results in paraesthesia rather than pain. ${ }^{5}$ These observations led to the conclusion that a purely mechanical process is insufficient to explain sciatica.

In the nineties several animal studies suggested that sciatica could be reproduced by applying the nucleus pulposus (NP) (the core of the vertebral disc) to a nerve root, in the absence of nerve root compression. ${ }^{6}$ This contact was sufficient to produce not only allodynia but also electrical and histological changes of the nerve compatible with acute sciatica. $^{7}$ In parallel, several authors have reported the presence of inflammatory mediators in human herniated disc tissue. ${ }^{8-11}$ Among these mediators, tumour necrosis factor
$\alpha(\mathrm{TNF} \alpha)$ has attracted much attention for, in addition to its detection in herniated discs and its key role in the inflammatory cascade, it has a neurotoxic effect when injected into the endonerve. ${ }^{12}$ The discovery that the application of TNF $\alpha$ alone, isolated from NP tissue, to nerve roots could reproduce the clinical and histological effects induced by the application of whole NP strongly supports a central role for TNF $\alpha$ in animal models of sciatica. ${ }^{13}$ The positive effect of TNF $\alpha$ inhibitors (infliximab, etanercept) in the treatment of animal models of sciatica ${ }^{14}{ }^{15}$ has reinforced this theory and opens the way for a new approach to the treatment of this disease, leading several editorialists to call for trials of anti-TNF $\alpha$ agents in human sciatica.

This pilot study was undertaken to test the hypothesis that TNF $\alpha$ inhibitors could be a potential alternative in the treatment of acute and severe sciatica and that $\mathrm{TNF} \alpha$ may participate in the pathogenesis of human sciatica.

\section{PATIENTS AND METHODS}

\section{Study design}

This is an open observational cohort study using historical controls.

\section{Patients}

After approval by the local ethics committee, 10 consecutive patients admitted to hospital for acute sciatica were recruited. Patients had to be over 18 years of age, able to give full informed consent, and to have had leg pain for less than 8 weeks. Sciatica was defined as unilateral leg pain following

Abbreviations: $\mathrm{CT}$, computed tomography; $\mathrm{MRI}$, magnetic resonance imaging; NP, nucleus pulposus; NSAIDs, non-steroidal antiinflammatory drugs; ODI, Oswestry Disability Index; RMDQ, Roland Morris Disability Questionnaire; TNF $\alpha$, tumour necrosis factor $\alpha$; VASB, visual analogue scale for back pain; VASL, visual analogue scale for leg pain 


\begin{tabular}{|c|c|c|c|}
\hline Demographic data & $\begin{array}{l}\text { Etanercept } \\
(\mathrm{n}=10)\end{array}$ & $\begin{array}{l}\text { Methyl- } \\
\text { prednisolone } \\
(n=10)\end{array}$ & p Value \\
\hline $\begin{array}{l}\text { Age (years), mean (SD) } \\
\text { Sex (male/female) }\end{array}$ & $\begin{array}{l}45.0(11.9) \\
6 / 4\end{array}$ & $\begin{array}{l}49.4(14.6) \\
4 / 6\end{array}$ & $\begin{array}{l}\text { NS } \\
\text { NS }\end{array}$ \\
\hline $\begin{array}{l}\text { Duration of sciatica (weeks), } \\
\text { mean (SD) }\end{array}$ & $2.7(1.8)$ & $3.7(5.5)$ & NS \\
\hline \multicolumn{4}{|l|}{$\begin{array}{l}\text { mean (SD) } \\
\text { Disc level: }\end{array}$} \\
\hline $\mathrm{L} 3-\mathrm{L} 4$ & 4 & 2 & NS \\
\hline$L 4-L 5$ & 2 & 4 & \\
\hline $\mathrm{L} 5-\mathrm{S} 1$ & $3^{*}$ & 4 & \\
\hline Muscle weakness & 6 & 6 & NS \\
\hline Sensory deficit & 6 & 7 & NS \\
\hline Reflex deficit & 5 & 5 & NS \\
\hline Past history of back pain & 5 & 6 & NS \\
\hline Past history of leg pain & 3 & 4 & NS \\
\hline
\end{tabular}

a dermatoma (L3, L4, L5, or S1) with signs of radicular irritation (reproduction of leg pain with the straight leg raising test or femoral nerve stretch test in the case of L3 or L4 involvement or with the Valsalva manoeuvre). Severity was defined by a visual analogue scale for leg pain (VASL) score of greater than 50 (on a scale from 0 to 100) and the need for hospitalisation (a decision that was taken by the admitting physician, not involved in the study). Exclusion criteria were the need for surgical intervention (patient presenting with progressive or major muscle weakness or with cauda equina syndrome), the presence of concomitant infection, past history of tuberculosis or cancer, signs of latent tuberculosis on chest $x$ ray examination, autoimmune disease except rheumatoid arthritis, and pregnancy or lack of efficient contraception.

\section{Comparison group}

All 10 patients who had been recruited to an earlier study of IV methylprednisolone in acute severe sciatica were used as controls for the present observations. These were 10 consecutive patients admitted to hospital for acute severe sciatica, fulfilling the same definition as used in the current study. Exclusion criteria were the same as for the current trial, except that evidence of latent pulmonary tuberculosis was not sought.

\section{Treatments}

The etanercept group was treated with subcutaneous etanercept $25 \mathrm{mg}$ on days 1,4 , and 7 . The historical group received IV methylprednisolone $250 \mathrm{mg}$ on days 1,4 , and 7 . Both groups received simple analgesics (including opioids if needed), NSAIDs, muscle relaxants, and physical therapy. Steroids were not given, apart from the study treatment of methylprednisolone. For both groups, the attending physician who was not involved in the study decided on hospital discharge. After hospital discharge all patients returned to their family physician who was entirely responsible for future clinical decisions (that is, surgery). There was no contact with the study team until the final evaluation (T2).

\section{Evaluation}

For both groups, a thoughtful clinical examination was performed on admission, and at regular intervals during hospitalisation. Back and leg pain were recorded with a VAS every day for the first 10 days and at week 6. Day 10 (T1) and week 6 (T2) were defined as the two times of evaluation. Functional impairment was evaluated with the Roland Morris Disability Questionnaire (RMDQ), ${ }^{16}$ modified to include the evaluation of leg pain, and Oswestry Disability
Index $(\mathrm{ODI})^{17}$ at inclusion (T0), $\mathrm{T} 1$, and $\mathrm{T} 2$. The primary outcome measures was VASL at T2. Other end points were VAS back pain score (VASB), raw functional scores (that is, RMDQ and ODI) at $\mathrm{Tl}$ and $\mathrm{T} 2$, and percentage of improvement for each of the variables (VASL, VASB, ODI, RMDQ) at T2. Patients achieving either VASL $<30$ or ODI $<20$ at T2 were defined as having good evolution. ${ }^{12}$

\section{Statistical analyses}

Statistical analyses were performed using SPSS version 11.0 (SPSS corporation, Chicago, IL). Fisher's exact test was used for dichotomous variables and the Mann-Whitney test for continuous variables. Statistical significance was defined as a $p$ value $<0.05$. To take into account all patients (that is, including patients who might have had surgery), analyses were also performed using the percentage improvement of each variable. Patients who underwent surgery were considered as failure (no improvement $=0 \%$ ) and an LOCF procedure (last observation carried forward) was used for missing data. As this was a pilot study no sample size calculation could be performed.

\section{RESULTS}

\section{Patients}

Twelve patients admitted to hospital with acute sciatica between May 2002 and June 2003 fulfilled the inclusion criteria and were offered etanercept treatment. Two refused to participate for personal reasons. The methylprednisolone group included 10 consecutive patients admitted to hospital for acute, severe sciatica between July 2001 and April 2002. There were no demographic differences between the two groups (table 1). All 20 patients had a positive straight leg raising test (or positive femoral nerve stretch test when appropriate) and at least one objective sign of nerve root compression (muscle weakness, sensitive disturbances, or decreased tendon reflex). There was a good concordance between clinical findings and radiological evidence of disc hernia (either CT scan or MRI) for the 19 available examinations. One patient in the etanercept group had clinical signs of S1 irritation and refused to have an MRI because she had a major clinical improvement before the scheduled appointment. One patient in the methylprednisolone group had leg pain for 16 weeks. Patients in both groups had severe leg pain and a high degree of functional impairment as indicated by the VASL, ODI, and RMDQ scores, without any significant difference between the two groups (table 2 ).

\section{Etanercept treatment group}

All 10 patients showed clinical improvement at Tl that was statistically significant for VASL, ODI, and RMDQ. Nine of them continued to improve between T1 and T2 (table 2). At T2, VASL had decreased from 74.4 (SD 12.9) to 12.4 (SD 13.2), RMDQ from 17.8 (SD 3.3) to 5.8 (SD 5.5), and ODI from 75.4 (SD 19.4) to 17.3 (SD 13.1), all $\mathrm{p}<0.001$. VASB decreased from 36.4 (SD 39.8) to 7.4 (SD 10.8), a difference that was not statistically significant owing to the large standard deviation. One patient had a relapse of leg pain 3 weeks after inclusion and required surgical intervention. In this case treatment was considered to have failed.

\section{Historical group}

T2 evaluation was slightly delayed compared with the etanercept group $(9.4 \vee 6.2$ weeks, $\mathrm{p}<0.05)$ as a result of the observational design of this study, and one patient refused to participate.

In this group, all variables (VASL, VASB, ODI, RMDQ) were better at $\mathrm{Tl}$ than at inclusion (T0) (table 2). These differences were significant for VASL, ODI, and RMDQ (all 
Table 2 Evolution of pain and functional scores

\begin{tabular}{|c|c|c|c|c|c|c|c|c|c|}
\hline & \multicolumn{3}{|l|}{ TO } & \multicolumn{3}{|l|}{ TI } & \multicolumn{3}{|l|}{$\mathrm{T} 2$} \\
\hline & $\begin{array}{l}\text { Etanercept } \\
(\mathrm{n}=10)\end{array}$ & $\begin{array}{l}\text { Methyl- } \\
\text { prednisolone } \\
(\mathrm{n}=10)\end{array}$ & $\mathbf{p}$ & $\begin{array}{l}\text { Etanercept } \\
(\mathrm{n}=10)\end{array}$ & $\begin{array}{l}\text { Methyl- } \\
\text { prednisolone } \\
(\mathrm{n}=10)\end{array}$ & $p$ & $\begin{array}{l}\text { Etanercept } \\
(\mathrm{n}=10)\end{array}$ & $\begin{array}{l}\text { Methyl- } \\
\text { prednisolone } \\
(\mathrm{n}=10)\end{array}$ & $p$ \\
\hline VASL 0-100 & 74.4 (12.9) & 75.1 (14.2) & NS & $20.2(16.6)$ & 25.5 (15.5) & NS & $12.4(13.2)$ & $52.9(25.1)$ & $<0.001$ \\
\hline VASB 0-100 & $36.4(39.8)$ & $39.8(29.2)$ & NS & $8.4(11.9)$ & $19.9(18.4)$ & NS & $7.4(10.8)$ & $47.6(28.5)$ & 0.002 \\
\hline ODI 0-100 & $75.4(19.4)$ & $62.4(11.7)$ & NS & $33.9(25.4)$ & $31.6(15.3)$ & NS & $17.3(13.1)$ & $33.4(13.0)$ & $<0.05$ \\
\hline RMDQ 0-24 & $17.8(3.3)$ & $15.5(2.9)$ & NS & $9.8(7.8)$ & $10.4(4.6)$ & NS & $5.8(5.5)$ & $11.1(4.6)$ & 0.1 \\
\hline \multicolumn{10}{|c|}{$\begin{array}{l}\text { Results are given as mean (SD). } \\
\text { TO, inclusion; T1, day 10; T2, week 6; SD, standard deviation; VAS, visual analogue scale; VASL, VAS leg pain; VASB, VAS back pain; ODI, Oswestry Disability } \\
\text { Index; RMDQ, Roland Morris Disease Questionnaire. }\end{array}$} \\
\hline
\end{tabular}

$\mathrm{p}<0.01$ ) but not for VASB. Between T1 and T2 most of the patients had increased pain or functional impairment, but at T2 VASL, ODI, and RMDQ were still significantly better than at T0 $(\mathrm{p}<0.05)$ One patient underwent a surgical procedure a week after enrolment because of persistent severe leg pain.

\section{Comparison of etanercept and methylprednisolone groups}

At Tl there was no difference between the two groups. But at T2 both pain (VASL and VASB) and functional scores (ODI) had significantly improved in the etanercept group compared with the methylprednisolone group (table 2). The difference in RMDQ score at $\mathrm{T} 2$ between the two groups was more than five points in favour of the etanercept group. This difference is considered clinically meaningful but did not reach statistical significance.

Data for the percentage of improvement were also analysed, a mode of analysis that can encompass all the 20 patients and where those who underwent surgery were considered as having $0 \%$ improvement. At T2 leg pain had improved by a mean of $75 \%$ in the etanercept group $v 17.6 \%$ in the methylprednisolone group $(\mathrm{p}<0.01)$. The results of both ODI $(67.2 \% v 40.3 \%)$ and RMDQ (63.4\% v 23.1\%) were also significantly better in the etanercept group than in steroid group $(\mathrm{p}<0.05)$ (fig 1$)$.

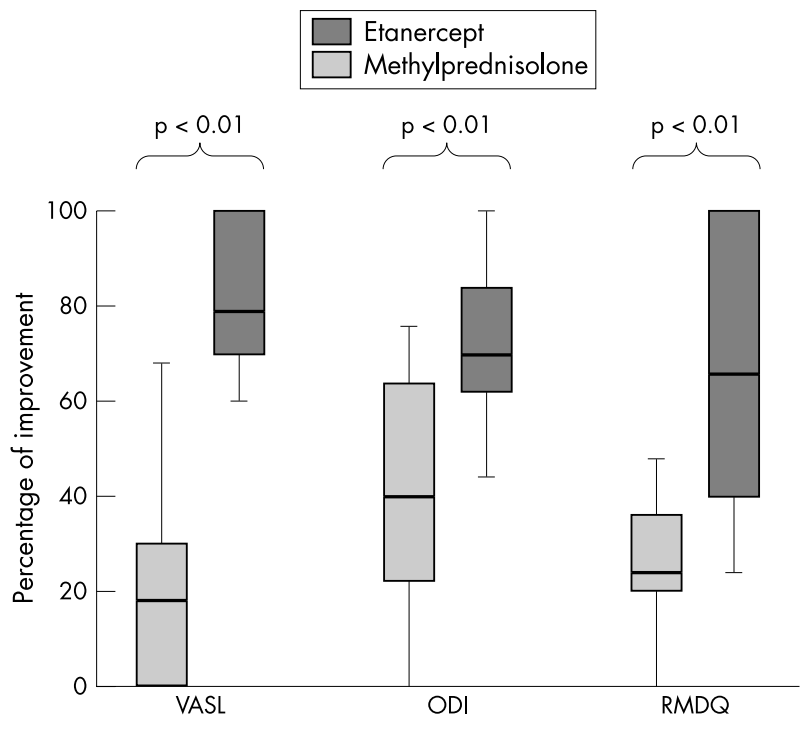

Figure 1 Percentage of improvement between TO and T2. The length of the box plots represents the interquartile range; means and extremes are also given. $0 \%=$ no improvement, $100 \%$ total recovery. VASL, visual analogue scale for leg pain; ODI, Oswestry Disability Index; RMDQ, Roland Morris Disease Questionnaire.
Eight of 10 patients in the etanercept group had VASL $<30$ $v$ only $2 / 10$ in the steroid group $(\mathrm{p}<0.05)$, and five achieved an ODI score $<20$ in the etanercept group $v$ two in the methylprednisolone group. Thus, $90 \%$ of the etanercept group comply with the definition of a good clinical result $v$ only $30 \%$ in the methylprednisolone group $(p<0.05)$. The mean hospitalisation time did not differ between the two groups (15 days).

\section{DISCUSSION}

Our results show that patients with acute, severe sciatica treated with a short course of TNF $\alpha$ inhibitor exhibit major clinical improvement at week 6 , as assessed by a measure of leg pain and functional scores. This supports the hypothesis that TNF $\alpha$ could play a central part in human acute sciatica.

Both etanercept and steroid treated patients improved at day 10. Patients in the etanercept group exhibited further improvement after 6 weeks. However, this was not the case for patients treated with methylprednisolone, some of whom had deteriorated by the time of the last evaluation. This difference might be related to a rebound effect in the corticosteroid group or, possibly, to a direct effect of TNF $\alpha$ on peripheral nerves besides its role in the inflammatory process. Consistent with this hypothesis, TNF $\alpha$ has been shown to induce pathogenic changes in peripheral nerves similar to those usually seen in neuropathic pain. ${ }^{13}$ Thus anti$\mathrm{TNF} \alpha$ treatment may be more effective in treating radiculopathy.

IV methylprednisolone has been used in our service for more than 20 years, as a result of the hypothesis that inflammation has a role in sciatica. Although we have empirical evidence of its effectiveness, no controlled trials have ever been published. Zufferey et al recently performed a placebo controlled study with IV methylprednisolone, in which only short term effect could be demonstrated. ${ }^{18}$ This would suggest that our control group is close to a placebo group.

Our results are supported by a recent study reporting the efficacy of infliximab in acute sciatica. ${ }^{19}$ The main difference between the two studies is the more rapid improvement in patients treated with infliximab $(50 \%$ improvement in pain score within 1 hour). This difference might be due to variations in pharmacokinetics or to the route of administration (intravenous $v$ subcutaneous).

No side effects were reported by the 10 patients treated in this study. Side effects feared with TNF $\alpha$ inhibitors are systemic allergic reactions and increased risk of infection, mainly tuberculosis. As these risks appear to be lower with etanercept than with infliximab, ${ }^{20}$ we tended to favour the use of the former for pilot studies on sciatica. It should also be remembered that sciatica is a potentially relapsing condition. Data on the use of infliximab in Crohn's disease showed that in the absence of concomitant use of immunosuppressive drugs, re-treating patients after a prolonged time 
interval increases the risk of an infusion reaction and decreases the efficacy of the drug. ${ }^{21}$

Although this study supports a potential role for TNF $\alpha$ inhibitors in the treatment of sciatica, these results should not be generalised. Firstly, the group studied was a highly selected group of patients with severe sciatica requiring admission to hospital. The benefit of this treatment may not be as significant when treating less severe symptoms, which generally have a higher rate of spontaneous favourable evolution. Secondly, only randomised controlled trials will provide a definitive answer about the role of $\mathrm{TNF} \alpha$ in the pathogenesis of sciatica and the potential of TNF $\alpha$ inhibitors for its treatment.

The cost of such treatments is a major concern, especially when considering the use of biological agents in a common condition. However, the cost of TNF $\alpha$ inhibitors has to be weighed against direct and indirect costs (length of hospital stay, days lost from employment, potential cost of surgery). The reduction of hospital stay or earlier return to work might justify the cost of this treatment. Further studies should also explore the cost effectiveness of $\mathrm{TNF} \alpha$ inhibitors in severe sciatica.

\section{ACKNOWLEDGEMENTS}

We thank Dr Trevor Duffy for his careful reviewing of, and comments on, the manuscript.

\section{Authors' affiliations}

S Genevay, S Stingelin, C Gabay, Division of Rheumatology, University Hospital of Geneva, 26 avenue. Beau-Séjour, 1211 Geneva 14, Switzerland

Disclosure: Etanercept was provided by Wyeth. None of the authors have received or will receive benefit for personal or professional use from a commercial party related directly or indirectly to the subject of this manuscript.

\section{REFERENCES}

1 Mixter WJ, Barr JS. Rupture of the intervertebral disc with involvement of the spinal canal. N Engl J Med 1934;211:210-15.

2 Deyo RA, Tsui-Wu YJ. Descriptive epidemiology of low-back pain and its related medical care in the United States. Spine 1987;12:264-8.

3 Waddell G. Low back pain: a twentieth century health care enigma. Spine 1996;21:2820-5.
4 Wiesel SW, Tsourmas N, Feffer HL, Citrin CM, Patronas N. A study of computer-assisted tomography. I. The incidence of positive CAT scans in an asymptomatic group of patients. Spine 1984;9:549-51.

5 Garfin SR, Rydevik B, Lind B, Massie J. Spinal nerve root compression. Spine 1995;20:1810-20.

6 Olmarker K, Rydevik B, Nordborg C. Autologous nucleus pulposus induces neurophysiologic and histologic changes in porcine cauda equina nerve roots. Spine 1993;18:1425-32.

7 Olmarker K, Nordborg C, Larsson K, Rydevik B. Ultrastructural changes in spinal nerve roots induced by autologous nucleus pulposus. Spine 1996;21:411-14.

8 Ahn SH, Cho YW, Ahn MW, Jang SH, Sohn YK, Kim HS. mRNA expression of cytokines and chemokines in herniated lumbar intervertebral discs. Spine 2002;27:911-17.

9 Goupille P, Jayson MI, Valat JP, Freemont AJ. The role of inflammation in disk herniation-associated radiculopathy. Semin Arthritis Rheum 1998;28:60-71.

10 Specchia N, Pagnotta A, Toesca A, Greco F. Cytokines and growth factors in the protruded intervertebral disc of the lumbar spine. Eur Spine $J$ 2002;11:145-51.

11 Kang JD, Georgescu HI, McIntyre-Larkin L, Stefanovic-Racic M, Donaldson WF 3rd, Evans CH. erniated lumbar intervertebral discs spontaneously produce matrix metalloproteinases, nitric oxide, interleukin-6, and prostaglandin E2. Spine 1996;21:271-7.

12 Wagner R, Myers RR. Endoneurial injection of TNF-alpha produces neuropathic pain behaviors. Neuroreport 1996;7:2897-901.

13 Igarashi T, Kikuchi S, Shubayev V, Myers RR. 2000 Volvo Award winner in basic science studies: Exogenous tumor necrosis factor-alpha mimics nucleus pulposus-induced neuropathology. Molecular, histologic, and behavioral comparisons in rats. Spine 2000;25:2975-80.

14 Onda A, Yabuki S, Kikuchi S. Effects of neutralizing antibodies to tumor necrosis factor-alpha on nucleus pulposus-induced abnormal nociresponses in rat dorsal horn neurons. Spine 2003;28:967-72.

15 Olmarker K, Rydevik B. Selective inhibition of tumor necrosis factor-alpha prevents nucleus pulposus-induced thrombus formation, intraneural edema, and reduction of nerve conduction velocity: possible implications for future pharmacologic treatment strategies of sciatica. Spine 2001;26:863-9.

16 Roland M, Morris R. A study of the natural history of back pain. Part I: development of a reliable and sensitive measure of disability in low-back pain. Spine 1983;8:141-4.

17 Fairbank JC, Couper J, Davies JB, O'Brien JP. The Oswestry low back pain disability questionnaire. Physiotherapy 1980;66:271-3.

18 Zufferey P, Finckh A, Schürch MA, Waldburger $M$, Balagué $F$, Ziadé $M$, et al. [Randomised, double blind, placebo controlled, study on short term efficacy of methylprednisolone in lombosciatica] [abstract]. Rev Rhum Ed Fr 2003;70:873.

19 Karppinen J, Korhonen T, Malmivaara A, Paimela L, Kyllonen E, Lindgren KA, et al. Tumor necrosis factor-alpha monoclonal antibody, infliximab, used to manage severe sciatica. Spine 2003;28:750-3.

20 Gardam MA, Keystone EC, Menzies R, Manners S, Skamene E, Long R, et al. Anti-fumour necrosis factor agents and tuberculosis risk: mechanisms of action and clinical management. Lancet Infect Dis 2003;3:148-55.

21 Baert F, Noman M, Vermeire S, Van Assche G, D'Haens G, Carbonez A, et al. Influence of immunogenicity on the long-term efficacy of infliximab in Crohn's disease. N Engl J Med 2003;348:601-8. 